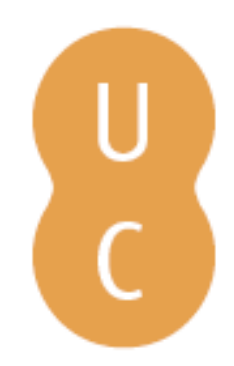

\title{
pommalina
}

\section{O uso do sistema de patentes pelas Universidades Brasileiras}

Autor(es): $\quad$ Oliveira, Luciana Goulart de; Nunes, Jeziel da Silva

Publicado por: Imprensa da Universidade de Coimbra

URL

persistente:

URI:http://hdl.handle.net/10316.2/31882

DOI:

DOI:http://dx.doi.org/10.14195/978-989-26-0869-3_3

Accessed : $\quad$ 26-Apr-2023 11:00:48

A navegação consulta e descarregamento dos títulos inseridos nas Bibliotecas Digitais UC Digitalis, UC Pombalina e UC Impactum, pressupõem a aceitação plena e sem reservas dos Termos e Condições de Uso destas Bibliotecas Digitais, disponíveis em https://digitalis.uc.pt/pt-pt/termos.

Conforme exposto nos referidos Termos e Condições de Uso, o descarregamento de títulos de acesso restrito requer uma licença válida de autorização devendo o utilizador aceder ao(s) documento(s) a partir de um endereço de IP da instituição detentora da supramencionada licença.

Ao utilizador é apenas permitido o descarregamento para uso pessoal, pelo que o emprego do(s) título(s) descarregado(s) para outro fim, designadamente comercial, carece de autorização do respetivo autor ou editor da obra.

Na medida em que todas as obras da UC Digitalis se encontram protegidas pelo Código do Direito de Autor e Direitos Conexos e demais legislação aplicável, toda a cópia, parcial ou total, deste documento, nos casos em que é legalmente admitida, deverá conter ou fazer-se acompanhar por este aviso. 
Maria Manuel Borges

Elias Sanz Casado

Coordenação

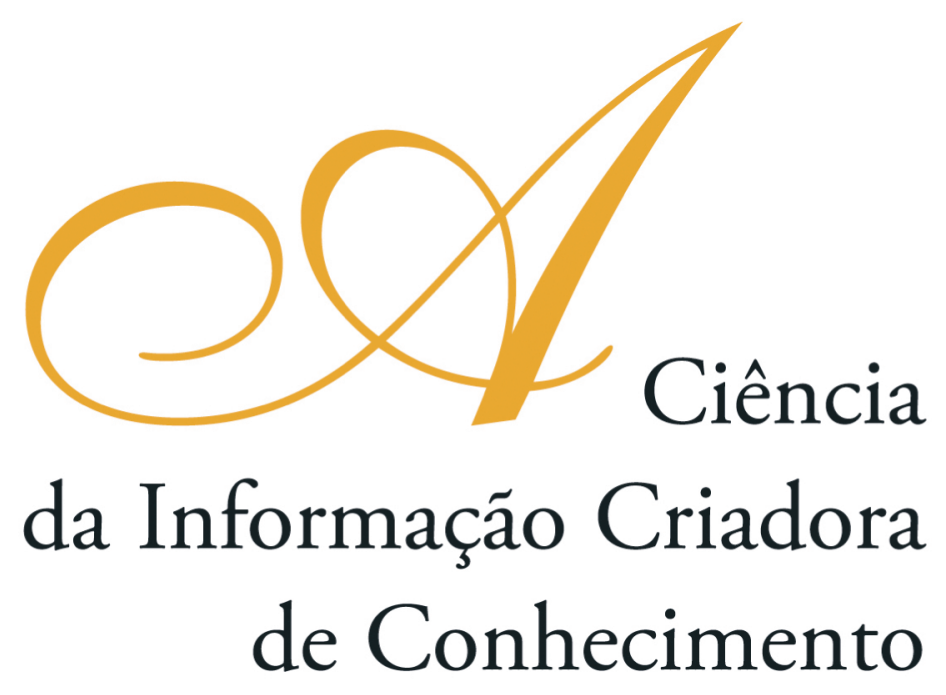

Vol. I I

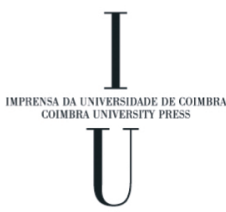

- COImbra 2009 


\title{
O uso do Sistema de Patentes pelas \\ UNIVERSIDADES Brasileiras
}

\author{
Luciana Goulart de Oliveira \\ Instituto Nacional da Propriedade Industrial (Brasil) \\ Jeziel da Silva Nunes \\ Instituto Nacional da Propriedade Industrial (Brasil)
}

\section{Resumo}

O objetivo do presente trabalho é o de apresentar uma visão da utilização do Sistema de Propriedade Industrial pelas instituições de ensino superior no Brasil, de modo a verificar o grau de apropriação, por meio de patentes, das tecnologias geradas endogenamente, bem como o uso das informaçôes contidas nos documentos de patentes, uma das mais ricas fontes de informação técnica disponível. Foi realizado um levantamento dos pedidos de patente depositados no INPI no período compreendido entre 2000 e 2004 e identificados os principais depositantes, a concentração tecnológica dos pedidos, distribuição regional dos depositantes, sua natureza jurídica e a existência de vinculação entre as entidades que possa denotar atividades de cooperação. As informaçóes disponíveis nos documentos de patente são importantes uma vez que apresentam uma descrição detalhada da invenção, podendo servir de base para novos desenvolvimentos técnicos, uma vez que compóem um repositório de conhecimento cumulativo e classificado ordenadamente.

\begin{abstract}
The present work aims to present a vision of the use of the Industrial Property System by the institutions of high education in Brazil, in order to verify the rate of appropriation, by means of patents, of the technologies generated internally, as well as the use of the information contained in patent documentation, one of the most rich sources of technical information available. A compilation of the patent applications applied to the National Institute of Industrial Property of Brazil in the period comprised between 2000 and 2004 was made and identified the main applicants, the technological concentration of the applications, regional distribution of the applicants, their juridical nature and existence of vinculation between institutions which could denote cooperation activities. The information available in patent documents are important because they disclose a detailed description of the inventions, serving as a base for new technical developments, as they form a vast repository of cumulative and orderly classified knowledge.
\end{abstract}

\section{Introdução}

As universidades e instituiçóes de ensino superior do Brasil vêm, ao longo do tempo, cumprindo seu papel de formação de recursos qualificados com competência e eficiência, apesar da falta de recursos que sempre atingiu o setor, e destacando-se no cenário internacional, no que diz respeito à produção e publicação científica. 
Dentro deste cenário, verifica-se que a universidade produz tecnologias em suas pesquisas que, de alguma maneira, solucionam problemas técnicos com utilidade para o país. Nos últimos anos, algumas açôes vêm sendo desenvolvidas no sentido de aproveitar esta expertise para a produçáo de bens e serviços de alto valor tecnológico, quer seja pelas Incubadoras de Base Tecnológica associadas às instituiçóes, quer seja através de parcerias diretamente com empresas.

Por outro lado, verifica-se também que a Academia praticamente não utiliza o sistema de propriedade industrial. Este afastamento conduz a duas conseqüências: a não proteção de seus eventuais desenvolvimentos que poderiam, em tese ter aplicaçóes comerciais pelas empresas e a não utilização das informaçóes disponíveis na documentação de patentes, que constitui, sem dúvida, uma fonte de informação importante para auxiliar as pesquisas. Isto se deve às características intrínsecas dos documentos e também pelo fato de que estudos já revelaram que dois terços de todo o conhecimento técnico só são publicados através da documentação de patentes [1] e, portanto, sua consulta deveria ser um pré- requisito ao se iniciar uma nova pesquisa.

Dentre as conseqüências resultantes do desconhecimento do sistema de propriedade industrial pelas universidades e instituiçôes de ensino superior no Brasil, cita-se, como exemplo, a não apropriaçáo de tecnologias patrocinadas com recursos públicos, a falta de remuneração e reconhecimento aos pesquisadores pelos desenvolvimentos realizados, a ausência de divulgação para a sociedade do acervo tecnológico produzido e existente na Academia, bem como o crescente dispêndio das empresas com a aquisiçáo de tecnologias exógenas.

Neste contexto o presente trabalho tem por objetivo oferecer uma visão da utilização do Sistema de Propriedade Industrial pelas universidades e instituiçóes de ensino superior no Brasil, no período de 2000 a 2004.

No Brasil, a Lei no 9.279/96, de 14 de maio de 1996, que regula a proteçáo dos direitos relativos à propriedade industrial, determina que o exame técnico para a concessão de uma patente seja realizado com a aferição de três requisitos básicos de patenteabilidade, que são: a Novidade, isto é, que a invenção não esteja compreendida no estado da arte, a Atividade Inventiva, isto é, que ela não seja uma decorrência evidente do estado da técnica e que a invenção tenha Aplicação Industrial, o que inclui aplicaçóes na agricultura, extração mineral e serviços.

Após a edição da Lei no 9.279/96¹ o Brasil passou a conceder, apenas, dois tipos de patentes: a Patente de Invenção e de Modelo de Utilidade. Adicionalmente, poderá ser concedido ao depositante do pedido de patente ou ao titular da invençáo um

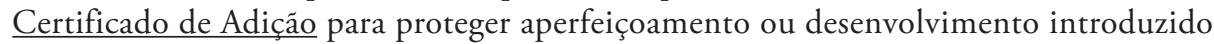
no objeto da invenção, mesmo que destituído de atividade inventiva, desde que a matéria se inclua no mesmo conceito inventivo. Neste caso, o Certificado de Adição é acessório da patente e tem a data de vigência desta.

De acordo com características adotadas internacionalmente no sistema de patentes os pedidos de patente depositados permanecem em sigilo por 18 meses, a partir do qual segue-se um prazo de até três anos, estipulado pela lei, para que o depositante

${ }^{1}$ O Código da Propriedade Industrial - Lei no $5.771 / 72$ possibiltava a concessão de quatro tipos de privilégio: Patente de invenção, modelo de utilidade, desenho industrial e modelo industrial. 
requeira o exame do pedido. Ao titular da patente é garantido o direito exclusivo de exploração do objeto, durante o período de vigência da patente, que é de 20 anos para a Patente de Invenção e de 15 anos para o Modelo de Utilidade, de modo a ressarcirse dos dispêndios em pesquisa e desenvolvimento, bem como do investimento que deverá realizar para colocar em prática seu invento. Em contrapartida ao privilégio temporário que o Estado concede a uma pessoa - física ou jurídica - a Lei exige que o relatório descritivo explique o objeto reivindicado de maneira suficiente e clara, de modo que um técnico no assunto possa realizá-lo e, quando for o caso, deve indicar a melhor forma para sua execução.

Dentre as inovaçóes introduzidas pela Lei no 9.279/96 encontra-se a possibilidade de que seja concedida patente a invençôes em todos os campos tecnológicos, significando que, a partir de 14 de maio de 1996, o Brasil passou a proteger, também, as áreas de fármacos, alimentos e produtos químicos, ficando, no entanto, excepcionada, dentre outras, a proteção por patente para o todo ou parte de seres vivos naturais e materiais biológicos encontrados na natureza, ou ainda que dela isolados, inclusive o genoma ou germoplasma de qualquer ser vivo natural e os processos biológicos naturais.

Os artigos 88 a 93 da Lei tratam, especificamente, da repartição de benefícios resultantes da Invenção ou Modelo de Utilidade, realizados por empregado ou prestador de serviço, tema de alta relevância no caso dos pesquisadores contratados pelas universidades públicas como professores e que tenham vinculação com a entidade. A Lei da Inovação, no 10.973, de 02 de dezembro de 2004, que dispóe sobre incentivos à inovação e à pesquisa científica e tecnológica no ambiente produtivo, regulamentada pelo Decreto no 5.563, de 11 de outubro de 2005, destaca o desafio de que o estabelecimento no país de uma cultura de inovação está amparado na constatação de que a produção de conhecimento e a inovação tecnológica passaram a ditar crescentemente as políticas de desenvolvimento dos países. Nesse contexto, o conhecimento é o elemento central das novas estruturas econômicas que surgem e a inovação passa a ser o veículo de transformação de conhecimento em riqueza e melhoria da qualidade de vida das sociedades.

\section{Metodologia do Presente Trabalho}

Os dados de patentes usados neste trabalho foram extraídos da Base de Patentes Brasileiras, do Instituto Nacional da Propriedade Industrial, tendo sido estabelecido o período de $01 / 01 / 2000$ até $31 / 12 / 2004$. Chama-se a atenção para o fato de que o trabalho só considerou os pedidos de patente que foram efetivamente publicados até o dia 31/12/2004. Ainda, só foram contabilizados os pedidos referentes a Patentes de Invenção (PI), Modelo de Utilidade (MU) e Certificado de Adição (C).

Após a etapa de adequaçáo dos dados migrados com a correçáo de erros de grafia, bem como harmonização dos nomes dos depositantes e dos inventores, foram incluídos os dados que não constam da base do SINPI, como a natureza jurídica dos depositantes e os tipos de vinculação entre os depositantes de um pedido de patente.

Na elaboração deste trabalho foi utilizado o Sistema Análise de Documento, que é uma ferramenta computacional que está sendo desenvolvida pelo INPI e que tem 
se mostrado eficiente para o tratamento das informações contidas na documentação de patentes, extraídas on line das diversas bases de dados de patentes disponíveis. Ademais, ela permite a inclusão de alguns dados que não estão presentes nas bases originais como, por exemplo: dados de localizaçáo dos depositantes, sua natureza jurídica, o local do depósito, tipo de relacionamento entre depositantes, dentre outros.

\section{Resultados Obtidos}

O levantamento realizado utilizando a metodologia especificada selecionou 784 documentos, sendo 713 patentes de invenção (91,94\%) e 62 modelos de utilidade $(7,91 \%)$ e a evolução da busca por proteção de patentes no período de 2000 a 2004 pode ser vista na Fig. 01.

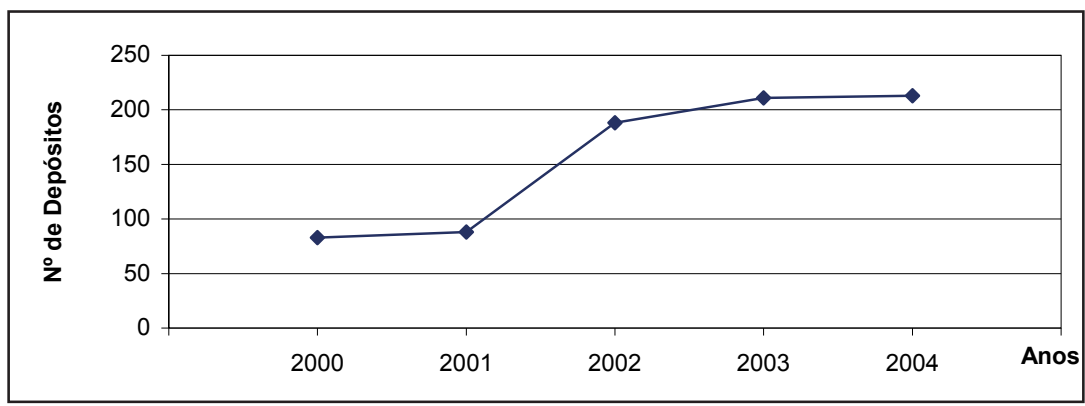

Fig. 1 - Evolução dos Depósitos das Universidades de 2000 a 2004

Fonte: sinpi/cedin/sistemaad

Concentra-se em 47 depositantes o total de 784 depósitos de pedidos de patentes efetuados pelas instituiçóes de ensino superior no país, constando na Tabela 1 o ranking.

Tabela 1 - Ranking dos Depositantes

\begin{tabular}{|l|l|l|l|l|}
\hline Instituiçáo & SIGLA & UF & $\begin{array}{l}\text { No } \\
\text { Doc. }\end{array}$ & $(\%)$ \\
\hline Universidade Estadual de Campinas & UNICAMP & SP & 232 & 29,37 \\
\hline Universidade Federal de Minas Gerais & UFMG & MG & 97 & 12,28 \\
\hline Universidade Federal do Rio de Janeiro & UFRJ & RJ & 81 & 10,25 \\
\hline Universidade de Sáo Paulo & USP & SP & 80 & 10,13 \\
\hline Universidade Federal do Rio Grande do Sul & UFRGS & RS & 41 & 5,19 \\
\hline Universidade Estadual Paulista Julio de Mesquita Filho & UNESP & SP & 37 & 4,68 \\
\hline Universidade Federal de Viçosa & UFV & MG & 27 & 3,42 \\
\hline Universidade Federal de Pernambuco & UFPE & PE & 23 & 2,91 \\
\hline Universidade Federal de São Carlos & UFSCAR & SP & 21 & 2,66 \\
\hline Universidade de Brasília & UNB & DF & 20 & 2,53 \\
\hline
\end{tabular}




\begin{tabular}{|l|l|l|l|l|}
\hline Universidade Federal de Sáo Paulo & UNIFESP & SP & 13 & 1,65 \\
\hline Universidade Federal do Pará & UFPA & PA & 12 & 1,52 \\
\hline Universidade Federal do Paraná & UFPR & PR & 11 & 1,39 \\
\hline Universidade Federal de Ouro Preto & UFOP & MG & 11 & 1,39 \\
\hline Universidade Estadual de Maringá & UEM & PR & 11 & 1,39 \\
\hline Universidade Federal de Santa Catarina & UFSC & SC & 10 & 1,27 \\
\hline Universidade de Caxias do Sul & UCS & RS & 7 & 0,89 \\
\hline Universidade Regional de Blumenau & FURB & SC & 5 & 0,63 \\
\hline Universidade Federal de Lavras & UFLA & MG & 4 & 0,5 \\
\hline Universidade Federal de Uberlândia & UFU & MG & 4 & 0,5 \\
\hline Universidade Federal Fluminense & UFF & RJ & 4 & 0,5 \\
\hline Universidade Católica de Brasília & UCB & DF & 3 & 0,38 \\
\hline Universidade de Ribeiráo Preto & UNAERP & SP & 3 & 0,38 \\
\hline Universidade Estadual de Londrina & UEL & PR & 3 & 0,38 \\
\hline Universidade do Estado do Rio de Janeiro & UERJ & RJ & 3 & 0,38 \\
\hline
\end{tabular}

Fonte: sinpi/cedin/sistema ad

A Universidade Estadual de Campinas (UNICAMP) se destaca como a líder absoluta dos depósitos efetuado pelas universidades, possuindo mais do dobro do número de depósitos da UFMG, que aparece na segunda posição. A UFRGS tem desempenho semelhante ao da UNICAMP em relação às demais instituições da Região Sul, da mesma forma que a UFPE e a UNB estão, respectivamente, para as Regióes Nordeste e Centro-Oeste.

Em termos gerais, a quantidade de depósitos das instituiçóes de ensino superior é muito pouco representativa relativamente ao total geral de depósitos efetuados no INPI no mesmo período, posto que retratam cerca de 2,3\% dos depósitos de residentes e $0,78 \%$ do total geral dos depósitos realizados no período.

Concentram-se na Regiáo Sudeste quase $80 \%$ dos depósitos de pedidos de patentes efetuados pelas instituiçóes de ensino superior, seguida pela Região Sul com $12 \%$ dos pedidos. A distribuição da concentração regional pode ser vista na Fig. 2, abaixo.

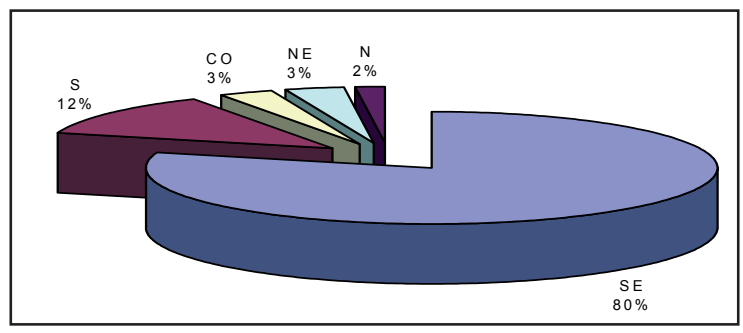

Fig. 2 - Concentração Regional

A Tabela 2 mostra o ranking dos depósitos, indicando o estado, a região do depósito, número de instituiçóes por estado e docentes alocados em cada entidade. 
Tabela 2 - Distribuição dos Depósitos por Região

\begin{tabular}{|c|c|c|c|c|}
\hline Regiáa & Estado & $\begin{array}{c}\text { No } \\
\text { Depósitos }\end{array}$ & $\begin{array}{c}\text { Instituiçóes por } \\
\text { Estado (1) }\end{array}$ & Docentes (1) \\
\hline SE & SP & 391 & 504 & 70.474 \\
\hline SE & MG & 146 & 289 & 30.353 \\
\hline SE & RJ & 89 & 118 & 32.777 \\
\hline S & RS & 55 & 83 & 19.557 \\
\hline S & PR & 29 & 94 & 22.396 \\
\hline NE & PE & 24 & 77 & 6.864 \\
\hline CO & DF & 23 & 66 & 7.397 \\
\hline S & SC & 15 & 158 & 14.526 \\
\hline N & PA & 12 & 25 & 4.443 \\
\hline N & AM & 2 & 18 & 3.644 \\
\hline CO & MT & 1 & 47 & 4.379 \\
\hline CO & MS & 1 & 41 & 4.014 \\
\hline NE & CE & 1 & 42 & 6.109 \\
\hline NE & SE & 1 & 11 & 1.578 \\
\hline
\end{tabular}

Fonte: sinpi/cedin/sistemaad/relatórios;(1) fonte: www.ibge.gov.br

A distribuição dos depósitos por Estado pode ser vista na Fig. 03.

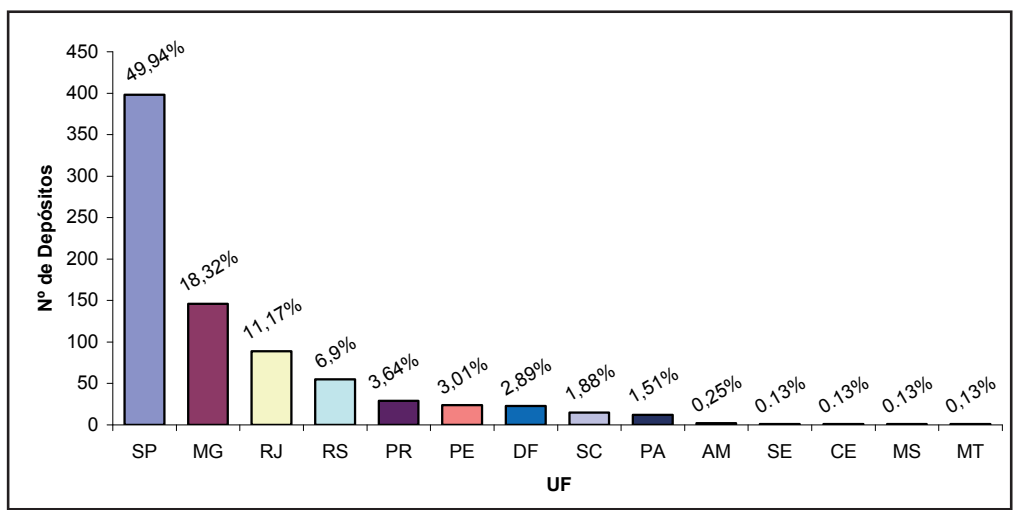

Fig. 3 - Distribuição por Unidade da Federação de 2000 a 2004 Fonte: sinpi/cedin/sistemaad/relatórios

\subsection{Natureza Jurídica dos Depositantes e Vínculos Institucionais existentes}

Objetivando uma melhor visualização foram estabelecidas as seguintes divisóes por categorias para a natureza jurídica dos depositantes: "pessoa física”, "pessoa jurídica pública", "pessoa jurídica privada”, "universidade pública”, "universidade privada”, "fomento público", "fomento privado", "fundação de amparo à pesquisa (FAP)", 
"núcleo de inovação tecnológica (NIT)", “instituto de pesquisa pública” e "instituto de pesquisa privado".

A distribuição dos depositantes pela natureza jurídica do vínculo existente entre depositantes que compartilham depósitos, sendo que a maioria dos depositantes é constituída por universidades públicas, em um total de $79 \%$, que podem estar, de alguma forma, associadas a um ou mais depositantes de natureza jurídica distinta, ou mesmo uma outra universidade.

Os depósitos referentes a pessoas físicas correspondem a 4\% e, na realidade, em sua grande maioria, têm como titulares pesquisadores pertencentes ao corpo docente das instituiçóes. Em outros casos, encontram-se depósitos onde também figuram pessoas jurídicas privadas, na proporção de $4 \%$ e que na sua grande maioria são empresas que se associaram às universidades para desenvolvimento conjunto.

As Fundaçóes de Amparo à Pesquisa - FAP's aparecem com um percentual de 3\% do total de depósitos, geralmente associadas às instituiçóes que utilizam seus recursos no financiamento da pesquisa. Os pedidos nos quais aparece uma FAP como titular isolada não foram considerados, por não pertencerem ao escopo do trabalho.

As universidades privadas representam apenas $2 \%$ do total, sendo que, na maioria das vezes, estão associadas a universidades públicas ou pessoas jurídicas públicas.

Os depósitos relativos aos institutos de pesquisa públicos referem-se não só aos institutos mas, também, às fundações de pesquisas, como é o caso da Fundação Oswaldo Cruz - FIOCRUZ, e só foram contados quando associados com universidades públicas ou privadas.

A natureza do vínculo entre os depositantes, de forma geral, retrata o tipo de relacionamento entre a instituição e seus parceiros nas suas atividades de pesquisa e, mais ainda, indica qual a abertura que a instituição está indicando para a sociedade. As possíveis categorias estabelecidas para a natureza do vínculo entre os depositantes foram criadas com a seguinte divisão: "compartilhada-universidade pública", "compartilhadauniversidade privada", "compartilhada-pessoa jurídica pública”, "compartilhada-pessoa jurídica privada" e "compartilhada-pessoa física". Estas categorias representam o tipo de relação existente entre os depositantes (dois ou mais) de um mesmo pedido de patente.

Devem ser observadas algumas características na utilização destas informações: os pedidos de patente com um único depositante foram enquadrados na categoria: "nãocompartilhado"; quando o depósito tinha como titulares duas ou mais universidades, adotou-se "compartilhado universidade pública ou privada" e, especificamente nestes casos, foram considerados na contagem como se cada titular tivesse um depósito, posto que não há maneira de saber qual a participação de cada um deles isoladamente.

Outro ponto que deve ser ressaltado refere-se aos casos dos depósitos efetuados por uma universidade tendo como segundo depositante uma ou mais pessoas físicas. Nestes casos, adotou-se, então, a denominação "compartilhada- pessoa física", mas somente foi contada a titularidade da Instituição (pessoa jurídica); quando o depósito foi efetuado por uma ou mais universidades juntamente com um instituto de pesquisa público ou privado, foi adotada a denominação "compartilhado com instituto de pesquisa público ou privado", respectivamente, e quando compartilhado com empresa pública ou privada foi designado como "compartilhado com pessoa jurídica pública ou privada”. 
No caso de haver compartilhamento entre universidade e instituição de fomento, criou-se uma separação entre as FAP's e as demais instituiçôes de fomento. Foi também previsto o compartilhamento entre as instituiçóes de ensino superior e os NIT's pois se pretende, em trabalhos futuros, identificar o papel exercido pelas instituiçóes de fomento no incremento ao patenteamento pelo setor acadêmico

A Figura 4 mostra a distribuição dos depósitos por natureza dos vínculos entre os titulares dos pedidos depositados no período.

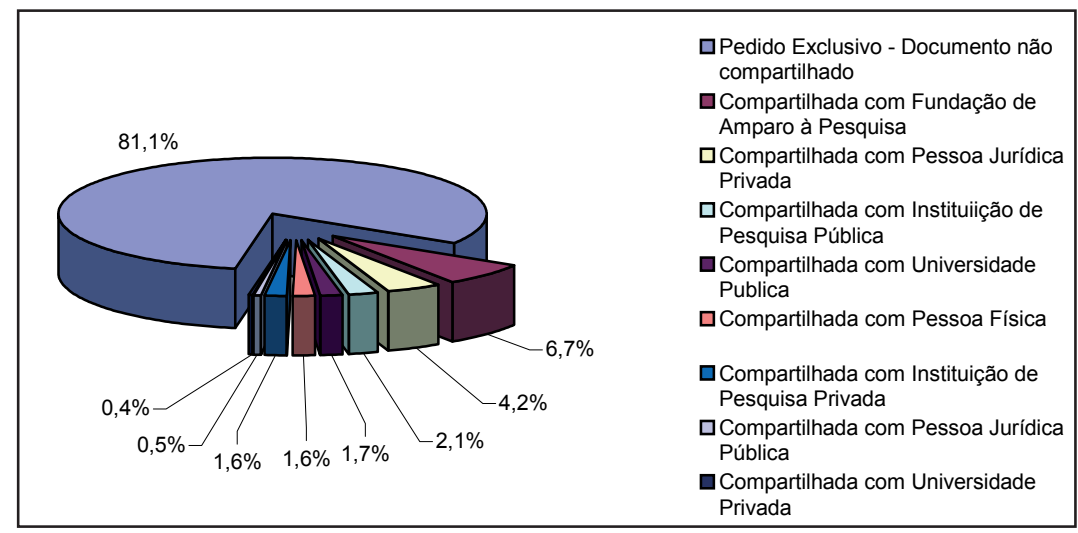

Fig. 4 - Tipos de Vínculo entre os Depositantes

Fonte: sinpi/cedin/sistemaad/relatórios

Verifica-se que a grande maioria dos depósitos tem um único titular, perfazendo um total de $81,6 \%$ dos depósitos, seguindo o mesmo perfil do trabalho anterior. Os demais pedidos são de titularidade compartilhada com as FAP's, 6,6\%, e com pessoas jurídicas, com $8 \%$. Já a colaboração entre universidades é de apenas $1,8 \%$ e com pessoas físicas de $1,4 \%$.

\subsection{Perfil dos Pedidos segundo a Classificação Internacional de Patentes}

A Classificação Internacional de Patentes - CIP é um meio internacionalmente usado para se estabelecer uma classificaçáo uniforme nos documentos de patentes depositados em qualquer escritório nacional e que tem por finalidade principal criar uma ferramenta de busca eficaz para a recuperaçáo dos documentos de patentes [3] permite identificar, com detalhes, o conhecimento tecnológico.

No presente trabalho somente a parte da classificação referente às oito Seçóes da CIP foi usada, objetivando revelar quais têm sido as áreas de pesquisa de interesse das universidades. O perfil dos depósitos classificados foi analisado, tendo sido verificado que a distribuição tecnológica está concentrada nas áreas de Química e Metalurgia, Necessidades Humanas e Física, como pode ser observado da Tabela 3. 
Tabela 3 - Perfil dos Depósitos segundo a CIP

\begin{tabular}{|l|l|l|l|l|l|l|l|}
\hline \multicolumn{2}{|l|}{ Seçóes da Classificaçáo de Patentes } & 2000 & 2001 & 2002 & 2003 & 2004 & Total \\
\hline A & Necessidades Humanas & 21 & 26 & 40 & 57 & 68 & 212 \\
\hline B & Operaçóes de Processamento; Transporte & 4 & 6 & 12 & 16 & 17 & 55 \\
\hline C & Química e Metalurgia & 39 & 30 & 80 & 70 & 72 & 291 \\
\hline D & Têxxteis e Papel & 2 & & 1 & 2 & 1 & 6 \\
\hline E & Construçóes Fixas & & 4 & 3 & 4 & 3 & 14 \\
\hline F & Eng. Mecânica; Iluminaçáo; Aquecimento; Armas & 4 & 1 & 11 & 5 & 9 & 30 \\
\hline G & Física & 9 & 11 & 31 & 40 & 33 & 124 \\
\hline H & Eletricidade & 3 & 6 & 9 & 15 & 10 & 43 \\
\hline
\end{tabular}

Fonte: sinpi/cedin/sistemaad/relatórios

\subsection{Principais Depositantes}

Em função do significativo número de pedidos depositados foram consideradas as instituiçóes que depositaram cinco ou mais pedidos e apenas 18 instituiçóes depositaram cinco ou mais pedidos de patentes no período em exame, ficando evidente que a UNICAMP lidera o ranking dos maiores depositantes do setor universitário, destacando-se com quase $30 \%$ do total de depósitos de universidades, seguida pela UFMG com $13 \%$, e a USP e UFRJ com cerca de $10 \%$ cada. A UNICAMP aparece em destaque com a expressiva média de 3,76 depósitos/mês, seguida da UFMG, com 1,58 depósitos/mês, da USP, com 1,33 depósitos/mês, e da UFRJ, com 1,23 depósitos/ mês. As demais instituiçóes têm uma freqüência de depósito inferior a 1 depósito/ mês. A evolução dos depósitos está na Fig. 5.

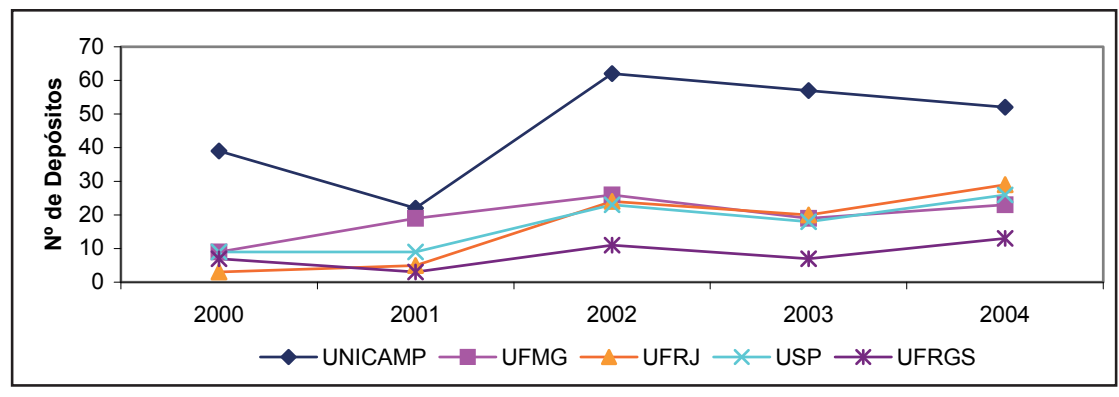

Fig. 5 - Evolução dos Depósitos dos cinco Maiores Depositantes Fonte: sinpi/cedin/sistemaad/relatórios

Uma das ações que fundamentou o incremento observado na UNICAMP pode ser identificada como a criação da Agência Inova, em 2003, cuja missão é fortalecer as parcerias da universidade com empresas, órgáos do governo e demais organizaçóes da sociedade, criando oportunidades para que as atividades de ensino e pesquisa se beneficiem dessas interaçóes, e contribuindo para o desenvolvimento econômico e 
social do país. A Inova concretizou um novo modelo de gestão, com a incorporação do aprendizado institucional acumulado em sua experiência nas áreas de transferência de tecnologia e inovação, além de sua importante atuação na proteção da propriedade intelectual, nos licenciamentos de patentes, transferências de know-how e parcerias com o setor empresarial privado.

Também na UFMG, a criação da CT\&IT em 1996, que começou a atuar em 1998, fundamentou a origem de um tratamento diferenciado para a questão da propriedade industrial na universidade, ao focar a disseminaçáo da cultura de PI, bem como a proteção e comercialização do conhecimento produzido internamente. Em realidade, os resultados obtidos na avaliação da concentração tecnológica do perfil dos pedidos depositados pela UFMG no período em exame também revelam a importância para o Estado de Minas Gerais do Arranjo Produtivo Local de Biotecnologia existente na região metropolitana de Belo Horizonte, relativamente ao surgimento de empresas de base tecnológica neste setor, ao aproveitamento dos recursos humanos de alta qualificação e ao desenvolvimento de tecnologias apropriadas pela universidade.

\subsection{Inventores Destacados}

Informação relevante constante nos documentos de patentes é aquela relativa ao inventor pois se tratada e analisada adequadamente, revela, em certa medida, o tipo e o grau de suas atividades objetivas, bem como se elas são contemporâneas (lembrando que um dos critérios de patenteabilidade é a novidade). Ademais traz, ainda, informaçóes de interesse comercial, posto que qualifica aqueles com grande incidência de depósitos de pedidos de patentes em uma determinada área como um especialista no assunto passível de fornecer consultoria para empresas que atuam no mesmo setor. Por outro lado, pode ser medida a efetividade da pesquisa tecnológica, já que o processo concessório da patente exige que o objeto reivindicado seja passível de aplicação industrial. A idéia é que, para a elaboração do pedido de patente, seja considerada alguma aplicação prática ou mesmo industrial. Um fato que deve ser considerado é que a relação acima cuida de cada inventor isoladamente, sem considerar o compartilhamento das invençóes, ou seja, inventores parceiros tiveram contados a seu favor todos os depósitos que possam ter efetuado com qualquer outro inventor pois náo há como saber qual a participação efetiva dos inventores que depositaram compartilhadamente um invento.

\subsection{Concentração Tecnológica dos Maiores Depositantes}

Os documentos de patentes têm como uma de suas características a classificação de seu objeto segundo a Classificação Internacional de Patentes que, no contexto deste trabalho, permite avaliar a atividade tecnológica desenvolvida pela instituiçáo no período de interesse. Sob a ótica do sistema de patentes, esta é a forma mais direta de verificar esta informaçáo já que toda a documentação encontra-se classificada segundo a CIP, que é utilizada pela maior parte dos países pertencentes ao sistema. 
As concentraçóes tecnológicas com base na CIP permitem visualizar para quais setores as instituiçóes estão canalizando seus esforços. $\mathrm{Na}$ apuração da concentração tecnológica levou-se em conta as três classificaçôes que registraram incidência de depósito maior que cinco em cada uma das instituiçóes, ordenadas pelo somatório de todas ocorrências, da maior incidência para a menor.

As principais instituiçóes do ranking concentraram seus esforços praticamente nas mesmas áreas, como é o caso da $\mathrm{A} 61 \mathrm{~K}$, que está sendo pesquisada pelas oito primeiras do ranking. Neste trabalho, só foi analisada a classificação principal, não sendo consideradas as classificações secundárias. Baseando-se unicamente na classificação principal, só é seguro verificar este tipo de concentração, ficando muito difícil inferir qualquer outra constatação referente ao uso e produçáo, o que só seria possível se analizássemos as demais classificaçóes secundárias.

\section{UNICAMP}

Verificou-se a expressiva ocorrência de subclasses relacionadas com "Tratamento de água, esgotos e lamas (C02F)" e "Investigação e análise de materiais por suas propriedades físicas ou químicas (G01N)", com mais de 20 ocorrências em cada uma delas. As atividades relacionadas às "Preparaçôes com finalidades médicas (A61K)", juntamente com o "Preparo de compostos usando enzimas e fermentaçôes (C12P)", também têm presença significativa, com ocorrências variando de 11 a 14 depósitos. Ainda na área de saúde, esta universidade desenvolve produtos na área odontológica (A61C), bem como busca proteção para compostos químicos orgânicos com atividade terapêutica $(\mathrm{C} 07 \mathrm{C}$ e D). Setor que também tem recebido atenção da UNICAMP é o de produtos orgânicos macromoleculares, sua preparação e demais processo correlatos (C08L e J).

\section{UFMG}

A UFMG tem seus pedidos concentrados na classificação A61K - Preparações com finalidades médicas, com 16 ocorrências. A universidade também tem pedidos na área A01N - Biocidas, com cinco pedidos e também demonstra interesse na pesquisa nas áreas de tratamento de efluentes $\mathrm{C} 02 \mathrm{~F}$, com quatro ocorrências e Investigação ou análise dos materiais pela determinação de suas propriedades químicas ou físicas - G01N, também com quatro ocorrências. Neste caso, fica evidente a concentração na área da A61K, provavelmente reflexo do Pólo de Biotecnologia próximo à Universidade.

\section{UFRJ}

A UFRJ concentra seus depósitos nas áreas A61K - Preparações para finalidades médicas, C07C e C07D - Compostos químicos orgânicos com finalidades terapêuticas e G01N - Investigação ou análise de materiais pela determinaçáo de suas propriedades. 
A USP concentra seus depósitos na área A61K - Preparaçóes com finalidades médicas, com 10 ocorrências, juntamente com a área $\mathrm{C} 12 \mathrm{~N}$ - Bioquímica, com seis ocorrências . Revela interesse também em buscar proteção na área A61M e A61B - Ciência Médica e Higiene e C07K - Peptídeos.

\section{UFRGS}

A UFRGS concentra seus depósitos nas áreas de Preparaçóes com finalidades médicas A61K, C07C - Compostos químicos, C12N - Microorganismos ou enzimas e G01N - Investigação ou análise de materiais.

\section{Conclusões}

O presente trabalho teve como objetivo precípuo o de levantar o número de depósitos de pedidos de patentes feito por instituiçôes de ensino superior brasileiras, no período compreendido entre 2000 e 2004 e algumas conclusóes foram possíveis. A primeira imediatamente vislumbrada é o baixo percentual de depósitos de pedidos levantados no referido período, representando apenas $2.3 \%$ dos de pedidos efetuados por residentes no Brasil no mesmo período. Uma segunda conclusão aponta para o fato de que, de uma forma geral, a Propriedade Industrial ainda é muito pouco conhecida e percebida pelo meio acadêmico do País, que ainda carece de uma cultura maior de desenvolvimento e apropriação das tecnologias geradas endogenamente. Este fato é ainda mais preocupante quando se contabiliza a totalidade de recursos investidos nas pesquisas efetuadas pelas universidades públicas, sem que haja maior preocupação com a busca por proteção destes desenvolvimentos por meio de patentes, bem como sua transferência para o mercado e uso pela sociedade. A Lei de Inovação, no 10.973, de 02 de dezembro de 2004, regulamentada pelo Decreto no 5.563 , de 11 de outubro de 2005, aporta uma nova situação para as instituiçóes de ensino e universidades públicas, na medida em torna compulsória a criação dos Núcleos de Inovação Tecnológica, com a finalidade de encaminhar todas as questóes de propriedade intelectual nascentes no meio acadêmico.

Outras constataçôes indicam uma forte concentração das pesquisas realizadas pela principais instituiçôes numa mesma área do conhecimento, o que pode significar uma falta de intercâmbio e de projetos de cooperação entre as instituiçóes, especialmente as de origem pública, para onde está carreada a maior parte dos recursos de pesquisa. Além disso a constatação de que a Região Sudeste concentra $80 \%$ dos depósitos, seguida pela Região Sul com $12 \%$, estando os $8 \%$ restantes distribuídos pelas demais regióes, reveste-se de importância, uma vez que pode significar um aporte maior de açôes governamentais em determinada região e que estejam possibilitando um alcance de níveis mais elevados de qualificação de recursos humanos, de interação universidade/empresas, de incorporação dos resultados das pesquisas no mercado e junto à sociedade. 
A concentração dos depósitos encontrados em São Paulo, em Minas Gerais e no Rio de Janeiro pode revelar tanto modelos exitosos de gestão como também realidades que devem ser alteradas, com a introduçáo de novos elementos indutores de desenvolvimento e de gerência de gestão do conhecimento.

Desdobramento interessante e agregador de valor a este tipo de estudo é a verificação, do ponto de vista estratégico, do grau de aderência das pesquisas desenvolvidas pelas universidades no Brasil comparadas com aquelas implementadas pelos seus pares internacionais, identificando possibilidades de projetos conjuntos e troca de experiências e expertises, bem como uma avaliação das competências já instaladas e o reconhecimento de setores potenciais a receberem investimentos.

Desta forma, fica evidente a existência de um campo vastíssimo de atuação para abordagens derivadas, fazendo um link entre a análise da informação de patentes e sua utilização em conjunto com dados econômicos para o planejamento estratégico de instituições, de políticas públicas e de diretrizes industriais.

\section{Referências bibliográficas}

[1] Marmor, A.C. et al (1979). The Technology assessment and forecast program of the United States Patent na Trademark Office. Wold Patent Information, Munchen, v.1, n.1 p. 15-23

[2] Assumpção, Eduardo (2000). O Sistema de Patentes e as Universidades Brasileiras nos Anos 90. Instituto Nacional da Propriedade Industrial, Rio de Janeiro

[3] Guia da Classificação Internacional de Patentes (2006) - Organização Mundial da Propriedade Intelectual. (oitava edição). Genebra

[4] Oliveira, Luciana G. (1992) Informação e a Propriedade Industrial no Brasil: a Ação do Instituto Nacional da Propriedade Industrial. Dissertação de mestrado EC/UFRJ/IBICT, Rio de Janeiro

[5] Gullo, Luci Mary G., \& Guerrante, Rafaela (2006). Maiores Depositantes de pedidos de patentes no Brasil, com Prioridade Brasileira. INPI/CEDIN/DIESPRO, Rio de Janeiro 